\title{
UMA FERRAMENTA PARA O ENSINO DO ACENTO PRIMÁRIO DO PB PARA FALANTES NATIVOS DO CRIOULO HAITIANO
}

A TOOL FOR TEACHING BRAZILIAN PORTUGUESE PRIMARY STRESS TO NATIVE SPEAKERS OF HAITIAN CREOLE

\author{
Adelaide Hercília Pescatori Silva ${ }^{1}$
}

\begin{abstract}
Resumo: Este trabalho apresenta uma ferramenta elaborada para o ensino de pronúncia do português brasileiro (PB) a falantes de crioulo haitiano. O aspecto de pronúncia focalizado é o acento primário de palavras no $P B$. Escolheu-se esse aspecto porque o acento primário é distintivo em PB: ele carrega diferenças de sentido e diferenças morfológicas, como a de tempo verbal. Porém, o crioulo haitiano é uma língua de acento previsível, a exemplo do francês, e por isso os haitianos, aprendizes de $P B$, tendem a transferir o padrão acentual do crioulo para a língua de acolhimento. O argumento norteador deste estudo é o de que a instrução explícita sobre a localização do acento primário, fornecida através da ferramenta aqui exposta, pode ajudar os haitianos a produzir o acento primário das palavras do $P B$ onde é esperado. Um teste envolvendo dois grupos - um exposto à ferramenta e outro não - parece confirmar sua eficiência.
\end{abstract}

Palavras-chave: português brasileiro; crioulo haitiano; acento primário; método de ensino.

Abstract: This paper presents a tool for teaching primary stress placement in Brazilian Portuguese (BP) to native speakers of Haitian Creole. The focus on primary stress comes from the fact that in BP primary stress is distinctive, in a way that its position within words entails lexical as well as morphological differences. Haitian Creole has a predictable primary stress location pattern, and native speakers of this language tend to transfer this pattern into BP. The teaching method employed is based on the assumption that explicit instruction on primary stress location can help native speakers of Haitian Creole to place the stress where it is expected by native speakers of BP. Preliminary results with Haitians learning $B P-$ some exposed to the method and others not exposed to it - suggest the tool plays an effective role in teaching BP primary stress location. Keywords: Brazilian Portuguese; Haitian Creole; primary stress; teaching method.

1 Doutora em Linguística pela Universidade Estadual de Campinas. Professora associada da UFPR. 


\section{Introdução}

A Universidade Federal do Paraná (UFPR) desenvolve já há dois anos o projeto de extensão "Português Brasileiro para Migração Humanitária" (PBMIH), que envolve docentes e alunos do Curso de Letras da UFPR, voltados ao ensino de português brasileiro (PB) como língua de acolhimento ${ }^{2}$. O maior contingente de estrangeiros atendidos é de haitianos, que chegam com frequência a Curitiba, onde somam, segundo dados da Polícia Federal, mais de 2,5 mil pessoas ${ }^{3}$. Atualmente o programa conta com nove turmas, organizadas em diferentes níveis ${ }^{4}$.

O grande desafio que se coloca para os envolvidos no projeto é a elaboração de material didático para atender a esta demanda, além do planejamento dos conteúdos a serem trabalhados em cada nível do curso.

Neste sentido, a primeira questão, mais geral, que emerge concerne à viabilidade de utilizar material já existente para ensino de PB como língua estrangeira. Uma outra questão, que decorre da primeira, relaciona-se à necessidade de ensinar pronúncia aos aprendizes e, em caso positivo, como fazê-lo.

Empregar material já existente para o ensino de $\mathrm{PB}$ como língua estrangeira não parece ser a melhor estratégia: deve-se levar em conta a condição especial na qual se encontram os haitianos que chegam ao Brasil, pois ao mesmo tempo em que aprendem a língua, a estão utilizando no seu cotidiano, o que configura uma situação obviamente distinta daquela vivida por um indivíduo que aprende uma língua estrangeira num curso de línguas convencional.

Alguns autores - como Grosso (2010), ao tratar do ensino do português europeu para imigrantes - frisam a situação peculiar dessa tarefa, chamando a atenção para o cenário de diversidade cultural e linguística decorrente do contato entre os imigrantes e os autóctones. Os imigrantes, segundo aquela autora, precisam ser linguisticamente autônomos num ambiente desconhecido. Assim, o país que acolhe os imigrantes tem de, entre outras atribuições, fornecer meios para que os imigrantes aprendam a língua de

2 Maiores detalhes sobre o projeto podem ser obtidos em https://www.facebook.com/ pbmih?fref=ts.

3 Cf. informação disponível em http://www.parana-online.com.br/editoria/cidades/news/841 $112 /$ ?noticia $=$ SINE + E $+A+P O R T A+D E+E N T R A D A+P A R A+H A I T I A N O S+E M+C U R I T I B A$ (Acesso em 25/11/2014).

4 Cabe esclarecer que a organização dos níveis nesse curso específico é semelhante à adotada pelo Centro de Línguas (CELIN) da UFPR: básico 1, básico 2, pré-intermediário, intermediário. Há, ainda, uma turma de letramento, necessária porque alguns dos imigrantes que chegam ao programa são iletrados mesmo em sua língua materna. 
quem os acolhe. Por isso, Grosso (2010) lança mão do conceito de "língua de acolhimento", diferenciando-o dos conceitos de "língua estrangeira" e "segunda língua":

A língua de acolhimento ultrapassa a noção de língua estrangeira ou de língua segunda. Para o público-adulto, recém-imerso numa realidade linguístico-cultural não vivenciada antes, o uso da língua estará ligado a um diversificado saber, saber fazer, a novas tarefas linguístico-comunicativas que devem ser realizadas na língua-alvo. (GROSSO, 2010, p. 68)

Partindo da premissa adotada neste estudo, segundo a qual o PB funciona como língua de acolhimento para os imigrantes haitianos, decorre a necessidade de se elaborar um material didático específico para o ensino de PB a falantes nativos de kreyò ${ }^{5}$.

A segunda questão colocada anteriormente, relativa à necessidade de se ensinar pronúncia aos imigrantes haitianos, encontra respaldo no fato de que o nível sonoro das línguas é o primeiro aspecto que chama a atenção de um indivíduo quando se depara com uma língua qualquer. Portanto, trazer a pronúncia do $\mathrm{PB}$ para o material didático é de grande importância no seu contexto como língua de acolhimento. Acrescente-se a este argumento a observação de Bauer e Alves (2011), segundo a qual muitos pesquisadores têm afirmado a importância do ensino de aspectos fonético-fonológicos de uma língua estrangeira. A despeito disto, comentam os autores, muitos livros didáticos de ensino de português como língua estrangeira não abordam a pronúncia de forma integrada com outras habilidades linguísticas.

Este estudo, então, trata de uma ferramenta elaborada especialmente para ensinar aos falantes nativos de kreyòl a produção do acento primário em $\mathrm{PB}$, assumindo que o $\mathrm{PB}$ funciona como língua de acolhimento para os imigrantes haitianos atendidos pelo projeto Português Brasileiro para Migração Humanitária da UFPR.

A razão pela qual se selecionou o aspecto prosódico mencionado, bem como a necessidade de abordá-lo em sala de aula, serão expostas nas próximas seções. Inicialmente, será exposto o arcabouço teórico no qual se baseia o presente estudo para, então, apresentar-se a ferramenta desenvolvida, baseada no que temos denominado "pautas acentuais". Finalmente, o texto relatará um pequeno teste rodado com três turmas distintas de

5 Doravante será esta a maneira como se referirá ao crioulo haitiano neste texto, porque esta é a forma como os nativos chamam sua língua. 
aprendizes de $\mathrm{PB}$, duas das quais não tinham tido acesso anterior à ferramenta. Os resultados apontam para a eficácia do método no ensino da produção do acento primário do $\mathrm{PB}$.

\section{Aspectos fonéticos e fonológicos do kreyòl: breve panorama}

Segundo Tardieu (2013), o kreyòl é uma língua que tem base lexical francesa -cerca de $80 \%$ a $85 \%$ dos itens lexicais teriam se originado dessa língua -, mas sua base gramatical provém de línguas africanas. Segundo o mesmo autor, seriam três as principais línguas africanas que constituem o kreyòl, todas pertencentes ao tronco nigero-congolês: ewe, fon, yorubá. Logo, se engana quem pensa que basta conhecer francês para compreender e falar o kreyòl.

O kreyòl é a língua oficial do Haiti. Segundo Cadely (2012), o kreyòl é falado por toda a população, que ele estima em aproximadamente nove milhões de pessoas em 2010, com base em dados não-oficiais. O Haiti reconhece também o francês como língua oficial, mas é preciso mencionar que esta língua é aprendida na escola apenas. Por isso, e considerando que boa parte da população haitiana não tem acesso à educação escolar, Cadely (2012) observa que os bilíngues, i.e., os haitianos que falam as duas línguas ${ }^{6}$, são minoria na população, correspondendo a aproximadamente um décimo dela.

O inventário de sons do kreyòl é constituído de sete vogais orais e cinco nasais, segundo Cadely (2004). O quadro abaixo ilustra o inventário:

\begin{tabular}{|c|c|c|c|c|}
\hline alta & $\mathrm{i}$ & $\tilde{\mathrm{i}}$ & & $\mathrm{u}$ \\
\hline & $\mathrm{e}$ & & & 0 \\
\hline média & & $\tilde{\mathrm{e}}$ & $\tilde{0}$ & \\
\hline & $\varepsilon$ & & & 0 \\
\hline baixa & $\mathrm{a}$ & $\tilde{\mathrm{a}}$ & & \\
\hline
\end{tabular}

Quadro 1 - Vogais do kreyòl, com base em Cadely (2004)

Como se vê, o quadro de vogais do kreyòl é muito parecido com o quadro de sons vocálicos do $\mathrm{PB}$, sobretudo no que concerne ao quadro das vogais orais: ambas as línguas apresentam, por exemplo, os mesmos graus

6 Esta é a acepção de Cadely (2012) para "bilingue". Como não é objetivo deste estudo discutir a acepção do termo, será mantida esta. 
de abertura. Por outro lado, o quadro das vogais nasais do kreyòl apresenta algumas diferenças quando comparado ao inventário de vogais nasais do $\mathrm{PB}^{7}$, sobretudo quanto à abertura das vogais nasais que, segundo a descrição do Quadro 1, seriam mais baixas do que as vogais nasais do PB. Cadely (2004) informa, ainda, que essas vogais têm caráter distintivo no kreyòl.

O inventário dos sons consonantais, por sua vez, é o seguinte:

\begin{tabular}{|c|c|c|c|c|c|c|c|c|c|c|c|c|}
\hline & \multicolumn{2}{|c|}{ Bilabiais } & \multicolumn{2}{l|}{ Labiodentais } & \multicolumn{2}{l|}{ alveolares } & \multicolumn{2}{c|}{$\begin{array}{c}\text { Pós- } \\
\text { alveolares }\end{array}$} & \multicolumn{2}{c|}{ palatais } & \multicolumn{2}{c|}{ velares } \\
\hline Oclusivas & $\mathrm{p}$ & $\mathrm{b}$ & & & $\mathrm{t}$ & $\mathrm{d}$ & & & & & $\mathrm{k}$ & $\mathrm{g}$ \\
\hline Nasais & & $\mathrm{m}$ & & & & $\mathrm{n}$ & & & & & & \\
\hline Fricativas & & & $\mathrm{f}$ & $\mathrm{v}$ & $\mathrm{s}$ & $\mathrm{z}$ & $\int$ & 3 & & $\mathrm{j}$ & & \\
\hline aproximantes & & & & & & $\mathrm{l}$ & & & & & & $\mathrm{\gamma}$ \\
\hline
\end{tabular}

Quadro 2 - Consoantes do kreyòl, com base em Cadely (2004)

Além dos sons consonantais dispostos no quadro, Cadely (2004) também relata a ocorrência das aproximantes lábio-velar [w] e lábio-palatal $[\mathrm{u}]$. O autor nota que a aproximante lábio-velar $[\mathrm{w}]$ e a aproximante palatal [j] se opõem na língua; por outro lado, a aproximante lábio-palatal [ч] tem distribuição restrita, ocorrendo apenas no início da palavra [uit] "oito" e seus derivados. Pode ocorrer também em posição medial de algumas palavras mas, de acordo com Cadely (2004), sempre seguida da vogal [i], o que permite pensar que tal aproximante resulta de um processo de assimilação de ponto da vogal [i]. A semivogal lábio-palatal não tem caráter distintivo na língua, conforme o autor.

O som classificado por Cadely (2004) como uma aproximante velar [y] ocorre em grupos consonantais tautossilábicos, seguindo obstruintes.

O Quadro 2 revela que o kreyòl tem apenas um som líquido, a lateral alveolar [1]. A aparente falta de oposição entre sons róticos e laterais traz uma dificuldade evidente para os haitianos aprendizes de PB, como a indistinção entre pares como "ela/era", por exemplo. Os grupos tautossilábicos com tap do $\mathrm{PB}$, por sua vez, ou são produzidos sem o som ou com o tap substituído pela aproximante lábio-velar ${ }^{8}$.

7 Não é objetivo deste estudo discutir a existência de vogais nasais ou nasalizadas no PB. Ainda assim, para uma caracterização fonética dessas vogais no PB, que reforça a comparação feita no texto, recomenda-se consulta a Seara et alii (2015).

8 Esta, no entanto, ainda é uma observação calcada em dados colhidos auditivamente. No próximo ano, deveremos iniciar estudos para averiguar se: 1) os haitianos percebem a distinção entre tap e lateral alveolar, mas não a conseguem produzir; 2) os haitianos não percebem nem produzem a distinção entre tap e lateral alveolar. A partir dos resultados obtidos tentaremos, então, desenvolver um método para o ensino da pronúncia do tap. 
Com relação aos aspectos prosódicos, há estudos escassos sobre o kreyòl. Uma das poucas descrições disponíveis é a de Finney (2004), que confirma a impressão auditiva que se tem ao escutar os falantes nativos dessa língua: o autor nota que, assim como o francês, o kreyòl atribui acento primário ao final da palavra. Portanto, ao contrário do $\mathrm{PB}$, o acento primário em kreyòl é previsível.

\section{Por que abordar o acento primário?}

Pennington (1996, apud BAUER e ALVES, 2011) argumenta que o ensino de pronúncia deve priorizar a inteligibilidade, a fluência e a acurácia. A autora define inteligibilidade como a habilidade que o aprendiz tem de ser entendido. A fluência, por sua vez, se relacionaria à capacidade que o aprendiz adquire de articular mais facilmente os sons da língua que aprende. Finalmente, a acurácia remete à precisão articulatória com que se produz um enunciado. Enquanto a acurácia requer um maior domínio da língua que se está adquirindo, a inteligibilidade é conditio sine qua non para que o aprendiz se faça entender já no início do processo de aquisição da língua estrangeira.

Considerando o PB como língua de acolhimento para os imigrantes haitianos, estes precisam produzir enunciados inteligíveis a todo momento no país que os acolhe, seja para procurar um emprego, seja para conversar com seus colegas de trabalho, seja ainda para buscar auxílio médico em caso de enfermidade. Portanto, conseguir a inteligibilidade de suas produções é fundamental.

Entretanto, considerando a tendência de um aprendiz transferir para a língua que adquire aspectos de sua língua materna, não é de se estranhar que os haitianos produzam sequências como "hoJE" ou "onTEM", por exemplo. Este fato configura o que Zimmer, Silveira e Alves (2009) denominam transferência fonético-fonológica e é encontrado não apenas na fala de haitianos recém-chegados ao Brasil, mas também na fala de haitianos que residem no país há mais tempo. A transferência pode afetar a inteligibilidade porque o acento primário é diferencial no $\mathrm{PB}$, conforme evidenciam pares como "CAqui/caQUI", ou o conhecido trio "SAbia/saBIa/ sabiA". O acento primário carrega, além da diferença semântica ilustrada por esses exemplos, diferença morfológica entre tempos verbais. Em pares

9 Neste texto parte-se do pressuposto, que será esclarecido nas seções seguintes, de que o domínio de aplicação do acento é a sílaba. Para marcar o acento primário se empregarão caracteres maiúsculos. 
como "cantaRÃO/canTAram"; "esqueceRÃO/esqueCEram"; "sorriRÃO/ soRRIram", a única diferença - considerando-se a cadeia da fala - é a posição do acento. $\mathrm{O}$ acento primário carrega, ainda, diferença entre a forma para a terceira pessoa do singular do presente do indicativo e o infinitivo dos verbos, como nos pares "Assa/aSSA"; "VENde/venDE"; "PARte/parTI"10.

Dados estes exemplos, a resposta à pergunta que intitula esta seção parece clara: é preciso abordar o acento primário como uma das maneiras de se buscar a inteligibilidade das produções dos imigrantes haitianos que aprendem $\mathrm{PB}$.

É óbvio que este não é o único aspecto que precisa ser tratado para garantir a inteligibilidade das produções dos imigrantes haitianos em PB. Porém, como mencionado na seção introdutória deste texto, a elaboração do material didático voltado ao ensino de $\mathrm{PB}$ para os falantes nativos de kreyòl está em sua fase inicial. Assim, é necessário partir de algum aspecto e este foi o escolhido porque, conforme relatado anteriormente, é claramente perceptível a um falante nativo de $\mathrm{PB}$ a transferência do padrão rítmico do kreyòl para a língua de acolhimento que os haitianos adquirem.

\section{Como ensinar o acento primário do PB aos falantes de kreyòl?}

Para que os haitianos possam passar a produzir o acento primário das palavras do PB no lugar onde é esperado, parte-se do princípio de que é preciso explicitar aos aprendizes como funciona o acento primário em $\mathrm{PB}$. Considera-se também a necessidade de que os aprendizes discriminem auditivamente os diferentes padrões acentuais e que eles pratiquem tais padrões.

Assim, para explicitar o funcionamento do acento primário em PB levaram-se em conta três aspectos: a) a frequência de ocorrência dos padrões oxítonos, paroxítonos e proparoxítonos; b) a noção de sílaba leve e sílaba pesada para atribuição do acento (cf. BISOL, 1992); c) os diferentes graus de intensidade entre sílabas tônicas, pretônicas e postônicas.

No que concerne à frequência de ocorrência dos padrões acentuais, Cantoni (2009) apresenta um levantamento feito a partir dos dados do Projeto ASPA ${ }^{11}$. De um total de 116.689 ocorrências, separadas em verbos (38.829 dados) e não-verbos (77.860 dados), aquela autora nota que as

10 Estes exemplos consideram a cadeia da fala e a recorrência do fenômeno do apagamento do $/ \mathrm{r} /$ em coda final de infinitivos verbais. O fato de serem grafados sem o "r" final visa a reforçar a ilustração do fenômeno mencionado.

11 O projeto ASPA, desenvolvido na Universidade Federal de Minas Gerais, sob coordenação da profa. Dra. Thaïs Cristófaro Silva, é um banco de dados de padrões sonoros do PB. Pode ser acessado em http://www.projetoaspa.org

Organon, Porto Alegre, v. 30, n. 58, p. 175-191, jan/jun. 2015. 
paroxítonas são maioria nas duas categorias, correspondendo a 71,4\% dos verbos e a $67,1 \%$ dos não-verbos. As oxítonas vêm bem atrás, correspondendo a $27,3 \%$ dos verbos e a $18,2 \%$ dos não-verbos. As proparoxítonas, por sua vez, constituem o padrão acentual menos frequente na língua e correspondem a $1,2 \%$ dos verbos e a $14,6 \%$ dos não-verbos. Estes dados possibilitam a generalização de que o padrão paroxítono é o mais frequente em $\mathrm{PB}$. Tem-se, então, um primeiro aspecto a ser considerado, sobre o funcionamento do acento primário em $\mathrm{PB}$.

A abordagem baseada na Fonologia de Uso, adotada por Cantoni (2009), coaduna-se com a abordagem baseada na Fonologia Métrica e empregada por Bisol (1992), para tratar do acento no PB.

Esta perspectiva prevê que o domínio de aplicação do acento primário em PB seja a sílaba. Em princípio, Bisol (1992) prevê que sílabas pesadas que contêm rima ramificada - atraiam acento, ao contrário de sílabas leves. Por outro lado, há palavras constituídas apenas de sílabas leves. Para explicar como o acento é atribuído nesses casos, Bisol (1992) prevê que a aplicação do acento primário é sujeita à Regra de Sensibilidade Quantitativa - que atribui acento à sílaba final de rima ramificada (BISOL, 1992: p. 71) - e à Formação de Constituintes Prosódicos - que estabelece relação forte/ fraco entre duas sílabas, concatenando uma sílaba leve à sílaba precedente. Como resultado, cria-se um constituinte binário mais à direita da palavra.

Estas duas regras, complementares, é que criam o acento primário das palavras em PB, segundo Bisol (1992). A previsão destas regras, e da complementaridade entre elas, dá conta de explicar o acento de palavras como, por exemplo, "TAça"; "caNEta”; "estoFAdo". Consequentemente, explica por que a grande maioria das palavras do PB são paroxítonas, como revelam os dados de Cantoni (2009).

Para os propósitos da ferramenta, neste seu primeiro momento, foram considerados os não-verbos. O tratamento para verbos será incorporado num momento seguinte, porque no nível do curso para o qual foi elaborado (Básico 1) tem-se trabalhado flexão verbal no tempo presente. Por isso, ainda não surgiu a necessidade de se diferenciar o tempo presente do tempo passado quanto ao padrão acentual.

Também neste momento não foi abordada, para a elaboração do método de ensino do acento primário em $\mathrm{PB}$, a extrametricidade na sílaba final. Este é um conceito proposto por Bisol (1992), para explicar dados como "ÁRvore" ou "FÓSforo", segundo a qual a extrametricidade dá conta especialmente de proparoxítonos. A atribuição de acento aos itens com padrão proparoxítono foi introduzida no modelo através do terceiro aspecto considerado para a explicitação do funcionamento do acento primário em $\mathrm{PB}$. 
O terceiro aspecto a ser considerado para explicitar o funcionamento do acento primário em $\mathrm{PB}$ se baseia num critério fonético, diferentemente dos dois primeiros, que focalizam aspectos fonológicos do acento primário. Trata-se da intensidade, um dos correlatos acústicos do acento em PB cf., e.g., Massini-Cagliari (1992); Moraes (1998).

A intensidade decorre da amplitude da onda sonora. Esta, por sua vez, consiste no aumento de pressão durante a produção de um som. No caso específico dos sons da fala, o aumento da pressão se relaciona ao aumento da força expiratória. O resultado auditivo do aumento da pressão de uma onda sonora é a percepção de um som mais forte - de volume mais alto - do que os sons vizinhos. Considerando estudos como os de Massini-Cagliari (1992) ou Moraes (1998), observamos que, numa sílaba tônica, não apenas a vogal é mais intensa do que as vogais de outras sílabas, mas também o são todos os demais sons constitutivos dessa sílaba tônica. Consequentemente, estes autores também consideram a sílaba como domínio de aplicação do acento.

Apesar de o comportamento das palavras isoladas não ser exatamente igual ao comportamento das palavras contextualizadas em enunciados, as observações de Moraes (1998) - que corroboram as de Massini-Cagliari, sobre o comportamento das palavras pertencentes a diferentes padrões acentuais - fornecem subsídios para a elaboração da ferramenta ora exposta. Assim, através de um estudo experimental, que lhe permitiu medir a intensidade das sílabas de palavras em meio de enunciado, o autor nota que:

1) palavras oxítonas têm a última sílaba com intensidade ligeiramente mais alta do que as sílabas pretônicas, cuja intensidade é muito próxima, quase igual entre si;

2) palavras paroxítonas têm a segunda sílaba com intensidade muito maior do que a da sílaba postônica. Por outro lado, a intensidade das silabas tônica e pretônica é muito parecida;

3) palavras proparoxítonas têm intensidade decrescente, da antepenúltima até a última sílaba. Consequentemente, a primeira sílaba postônica tem intensidade intermediária à da tônica e à da átona final.

É possível, então, a partir destas informações, propor um comportamento geral para o acento primário em $\mathrm{PB}$ : o domínio de aplicação de acento tônico é a sílaba. A maioria das palavras em PB levam acento na segunda sílaba, contando-se as sílabas de uma palavra do final para o começo. Temos, como exemplo: "GAto"; "baNAna"; "abaCAte". Entretanto, se houver na palavra uma sílaba pesada, i.e., com coda ramificada, a sílaba pesada atrai o acento primário, fato que pode acarretar em outro padrão acentual como, por exemplo, em "profeSSOR"; coraÇÃO; "raPAZ". A síla- 
ba tônica será aquela com volume mais alto, ou percebida auditivamente como a mais "forte" da palavra.

Tendo explicitado a maneira como o acento é atribuído às palavras do $\mathrm{PB}$ e a maneira como ele funciona, é possível, finalmente, passar à exposição da ferramenta elaborada para ensinar a localização do acento primário das palavras do $\mathrm{PB}$.

\section{Uma ferramenta para o ensino da produção do acento primário das palavras do $P B$}

Para ensinar aos falantes nativos de kreyòl a alocação do acento primário no $\mathrm{PB}$ é preciso, ao mesmo tempo, fazê-los perceber onde recai o acento, para então produzi-lo ${ }^{12}$. Considerando os aspectos do acento primário abordados na seção 3, bem como a estrutura acentual do kreyòl exposta na seção 2, elaborou-se uma ferramenta baseada em "pautas acentuais".

A ideia é que essas pautas funcionem como uma versão muito simplificada de pautas musicais, e que o acento primário seja tratado como um aspecto da "melodia da fala". Note-se que, de fato, o acento primário é um aspecto da prosódia do $\mathrm{PB}$, mas os termos técnicos, por óbvio, não serão apresentados aos alunos numa ferramenta didática.

Nessas pautas há três linhas. Cada uma delas corresponde a um nível de acento, considerando-se a distinção entre tônicas, pretônicas e postônicas, com base no estudo de Moraes (1998), por exemplo. O nível mais alto do acento - percebido como o "mais forte" da palavra - é alocado na primeira linha (de cima para baixo) e o nível mais baixo de acento, por conseguinte, é alocado na última linha da pauta. $\mathrm{O}$ acento das sílabas é sinalizado por uma bolinha. Assim:

\begin{tabular}{|c|c|c|c|c|c|c|c|c|}
\hline & & & \multicolumn{3}{|c|}{$\bullet$} & - & & \\
\hline$\bullet$ & $\bullet$ & & $\bullet$ & & & & $\bullet$ & \\
\hline • & & $\bullet$ & . & & $\bullet$ & & & • \\
\hline fé & bo & la & $\mathrm{ca}$ & ne & $\mathrm{ta}$ & lâm & pa & $\mathrm{da}$ \\
\hline
\end{tabular}

Quadro 3 - Exemplos de pautas acentuais do PB ilustrando diferentes padrões acentuais

12 A relação entre percepção e produção de fala é extremamente mais complexa do que aparentemente pressupõe esta relação biunívoca. Considerando, entretanto, que não é objetivo deste estudo investigar a relação entre produção e percepção de fala, assume-se por ora, para os propósitos deste trabalho, esta supersimplificação. 
Os exemplos do Quadro 3 foram os mesmos fornecidos aos alunos da turma de Básico 1, na primeira vez em que as pautas acentuais lhes foram apresentadas. Isto aconteceu no dia 02 de agosto de 2014, pouco menos de um mês depois do começo do semestre letivo, iniciado em 19 de julho ${ }^{13}$.

Observe-se que os exemplos contemplam os três padrões acentuais existentes: oxítonos; paroxítonos; proparoxítonos. Entretanto, esta nomenclatura não é utilizada. A abordagem prevê que os alunos saibam qual é a sílaba "mais forte", i.e., mais intensa da palavra, convencionando-se, para isso, que a primeira sílaba da palavra lâmpada seja "da"; a segunda, "pa" e a terceira, "lâm".

Observe-se também que a pauta é sempre a mesma - com três linhas independentemente de a palavra ter ou não três níveis de acento. No caso de "café" ou "bola", uma linha deixa de ser preenchida. Mais uma vez cabe comentar que o critério envolvido na marcação do nível do acento é que o mais intenso seja o mais alto na pauta, independentemente de a palavra ter duas ou três sílabas. Esta observação decorre da assunção - baseada na Teoria Métrica - de que toda sílaba de uma palavra tem ao menos um nível de acento.

No caso de palavras com quatro ou mais sílabas, e.g., "abacate", assume-se que as duas primeiras pretônicas tenham o mesmo nível de acento, intermediário ao da postônica e ao da tônica.

Quando o Quadro 3 foi apresentado aos alunos, ofereceu-se também a seguinte descrição do padrão acentual do PB:

A melodia da língua portuguesa alterna sílabas fortes e fracas. A maioria das palavras da língua portuguesa tem a penúltima sílaba mais forte, mas existem palavras nas quais a última sílaba é a mais forte. Existem também algumas palavras nas quais a antepenúltima sílaba é a mais forte.

Podemos representar graficamente a "força" (acento) em língua portuguesa através de pautas. Nelas, cada bolinha representa o acento de cada sílaba. Quanto mais alta a bolinha estiver na pauta, maior o acento da sílaba. (SILVA, 2014)

Como se vê, a explicação pressupõe que os alunos consigam perceber auditivamente qual sílaba leva o acento primário em PB. Por isso, foi tomado o cuidado adicional de sinalizar com a mão o padrão acentual de uma palavra. Assim, a mão sobe ou desce, acompanhando a evolução da intensidade das sílabas de uma palavra, e como que regendo os alunos. Na sequência, os

13 Cabe adicionar que as aulas acontecem nas tardes de sábado e têm duração de três horas. Este horário foi estabelecido em função dos compromissos profissionais dos haitianos, que os impedem de fazer aulas durante a semana, mesmo no período noturno. 
alunos são instados a produzirem a palavra pelo menos três vezes depois de a ouvirem, e, seguindo o exemplo que lhes foi fornecido, a movimentarem a mão de acordo com a evolução da intensidade das sílabas de uma palavra. Esclarece-se aos alunos que a posição mais alta da mão coincide com a sílaba de maior intensidade, que é a sílaba que leva o acento primário.

Logo na primeira aula em que a pauta foi usada, depois de fornecida a explicação transcrita acima, os alunos foram instados a preencher a pauta acentual de dez palavras. Todas as palavras foram utilizadas na aula, que versava sobre profissões.

Os alunos não demonstraram dificuldade em entender o funcionamento das pautas, mas tiveram dificuldades para preenchê-la, sobretudo porque tendiam a marcar o acento primário na primeira sílaba da direita para a esquerda, transferindo para o $\mathrm{PB}$ o padrão acentual do kreyòl.

Houve também dúvida sobre o padrão acentual da palavra "professor". Vários marcaram o acento primário na segunda sílaba. Quando noticiados de que o acento primário recai sobre a primeira sílaba, um dos alunos quis saber por que, especialmente considerando que a maioria das palavras do PB leva acento na segunda sílaba. Para explicar ao aluno a razão de "professor" levar acento na primeira sílaba, lançou-se mão dos conceitos de "sílaba leve" e de "sílaba pesada". Por uma simplificação didática, e considerando que as noções de consoante e vogal são noções elementares, foi-lhes ensinado que sílabas pesadas terminam em consoantes, ao contrário das sílabas leves, que terminam em vogais. Além disso, foi esclarecido que as sílabas pesadas exibem tendência a atrair o acento primário das palavras em PB. Portanto, sendo a primeira sílaba de "professor" uma sílaba pesada, não é de se estranhar que ela é que carregue o acento primário. Aparentemente, os alunos não tiveram dificuldade em entender a explicação.

Nas aulas que se seguiram, as pautas foram retomadas: desde o início de agosto, até o final de dezembro, quando o semestre letivo se encerrou, foram muito poucas as aulas em que não houve o trabalho com as pautas acentuais. A cada aula, eram selecionadas aproximadamente dez palavras. As palavras eram sempre selecionadas em função do tema da aula, de modo que todas elas tinham sido usadas nas atividades desenvolvidas. As pautas, então, eram a última atividade da aula, para a qual se reservavam aproximadamente vinte minutos.

À medida que o semestre foi caminhando, os alunos foram aparentemente melhorando sua pronúncia no que concerne à alocação do acento primário, e os exercícios com as pautas acentuais foram-se tornando prazerosos, a ponto de, durante a aula, ainda que não fosse o momento da atividade com as pautas acentuais, quando surgia alguma dúvida sobre 
o lugar do acento primário, as perguntas eram sempre acompanhadas da mão que "regia" a "melodia" da palavra.

O aparente sucesso do método fez, então, surgir uma questão: os exercícios com as pautas acentuais estariam, efetivamente, contribuindo para a percepção e a produção do acento primário das palavras em PB? Para tentar respondê-la, procedeu-se a um teste, que comparava o desempenho dos alunos da turma de Básico 1 com o desempenho de outras duas turmas. A próxima seção expõe, em detalhes, o teste e os resultados obtidos.

\section{Teste de alocação do acento primário}

A elaboração do teste para verificar a eficiência do método para o ensino da produção do acento primário em PB se valeu de estratégia similar àquela adotada nos exercícios conduzidos durante as aulas: um conjunto de palavras foi apresentado aos alunos, que deveriam marcar os acentos e seus níveis nas pautas correspondentes a cada palavra.

O teste, porém, foi rodado em duas outras turmas, que funcionaram como um grupo controle. Uma dessas turmas era outra turma de Básico 1, que foi aberta com o semestre letivo já em andamento e em razão da alta demanda por esse nível inicial do curso. A professora tinha iniciado o trabalho com as pautas duas semanas antes da aplicação do teste. A outra turma era uma turma do nível Pré-intermediário ${ }^{14}$, que até então não tinha trabalhado com o ensino do padrão acentual das palavras em PB.

Com o auxílio das duas outras professoras, foi selecionado um conjunto de trinta e três palavras, todas conhecidas pelos alunos das três turmas envolvidas. Do total, dez palavras eram oxítonas, quinze paroxítonas, e 8 proparoxítonas, conforme se observa no Quadro 4.

\begin{tabular}{|c|c|c|c|c|c|c|}
\hline \multicolumn{2}{|c|}{ Oxítonas } & \multicolumn{3}{c|}{ Paroxítonas } & \multicolumn{2}{c|}{ Proparoxítonas } \\
\hline profissão & professor & cidade & parente & escola & máquina & médico \\
\hline pintor & arroz & hora & hoje & restaurante & vômito & árvore \\
\hline misturar & computador & estrangeiro & cabeça & Curitiba & ônibus & estômago \\
\hline você & parabéns & empresa & criança & ontem & público & \\
\hline colocar & construção & parede & fácil & pedreiro & música & \\
\hline
\end{tabular}

Quadro 4 - Corpus de palavras utilizadas no experimento

14 Considerando a organização do curso, a turma de pré-intermediário já havia passado pelos níveis básico 1 e básico 2 . Os alunos estavam, portanto, no terceiro semestre do curso de língua portuguesa. 
O corpus tenta se aproximar da distribuição dos padrões acentuais no PB: por isso, há um número maior de paroxítonas, ao mesmo tempo em que o número de oxítonas supera o de proparoxítonas. As palavras foram lidas, em ordem aleatória, por um locutor desconhecido dos alunos que realizariam o teste. O locutor, do sexo masculino, tinha 50 anos na época da gravação. O cuidado de pedir para que outra pessoa, que não um professor do projeto, gravasse os dados, objetivava neutralizar uma possível familiaridade dos alunos com a pronúncia de suas professoras. Solicitou-se ao locutor que não produzisse o efeito prosódico de leitura de lista, porque o efeito poderia confundir os alunos. A gravação foi feita em sala silenciosa, através do software Audacity, versão 2.0.3. Através do mesmo software, inseriu-se um minuto de silêncio entre uma palavra e outra. A gravação do corpus foi copiada em três CDs, um para cada turma envolvida no experimento. Assim, todos os alunos foram expostos aos mesmos dados, numa mesma ordem de apresentação, para garantir iguais condições a todos os participantes.

A instrução fornecida aos alunos, antes do início do teste, foi a mesma fornecida no material didático e transcrita na seção 4. Os alunos, então, deveriam escutar as palavras gravadas e marcar os níveis de acento nas pautas correspondentes a cada palavra, durante o minuto intermediário entre uma palavra e a seguinte.

O número de participantes em cada turma e a média de acertos por turma são fornecidos na Tabela 1. Nela, B1 é o grupo experimental, correspondente à turma de básico 1, exposta ao método desde agosto. C1 e C2 são, respectivamente, as turmas do grupo controle e que tiveram pouca ou nenhuma exposição ao material didático antes da aplicação do teste. $\mathrm{C} 1$ corresponde à turma de nível pré-intermediário e $\mathrm{C} 2$ à outra turma de básico 1 .

\begin{tabular}{|c|c|c|c|}
\hline Grupos & Participantes & Média de acertos/ turma (\%) & Pautas adequadas ( $\geq \mathbf{1 7}$ palavras) \\
\hline B1 & 15 & 19,92 & $25(75,8 \%)$ \\
\hline C1 & 12 & 20,58 & $22(66,7 \%)$ \\
\hline C2 & 9 & 15,22 & $16(48,5 \%)$ \\
\hline
\end{tabular}

Tabela 1 - Número de participantes e média de acertos por grupos de participantes do experimento

Os dados da Tabela 1 sugerem a eficácia da ferramenta proposta para a produção e a percepção do acento primário em PB: B1, que esteve exposta à ferramenta, ao longo do semestre, registrou média de 19,92\% de pautas adequadas. Este é um percentual muito próximo ao obtido por $\mathrm{C} 1$, 
uma turma mais avançada e que obteve percentual de $20,58 \%$ de pautas adequadas. Além de a diferença entre os percentuais de acerto ${ }^{15}$ dos dois grupos ser muito pequena ${ }^{16}$, há que se considerar que os alunos do grupo C1 têm tempo maior de instrução formal no curso ofertado pela UFPR, comparativamente aos alunos dos grupos $\mathrm{B} 1$ e $\mathrm{C} 2$. Os alunos do grupo $\mathrm{C} 1$ têm também um maior tempo de permanência no Brasil: a média da turma é de 10,3 meses. Os alunos do grupo B1, por outro lado, têm uma média de 8,2 meses de permanência no Brasil ${ }^{17}$. Considerando o PB como língua de acolhimento e considerando, por conseguinte, que os alunos utilizam o PB diariamente em seu trabalho, por exemplo, o índice médio alcançado pela turma B1, exposta à ferramenta didática para alocação do ensino primário em $\mathrm{PB}$, parece mesmo indicar a viabilidade da instrução proposta.

A eficiência da ferramenta didática é reforçada pela comparação do número de pautas acentuais adequadas fornecidas por cada grupo. Por "pauta acentual adequada" entende-se, aqui, a pauta na qual os níveis de intensidade das sílabas constituintes das palavras seguem os níveis verificados no PB. A Tabela 1 evidencia que o grupo B1 apresentou o maior número de palavras com pautas acentuais adequadas: foram 25 , ou $75,8 \%$ do total de palavras do corpus. Os alunos do grupo $\mathrm{C} 1$ forneceram as pautas acentuais esperadas para 22 palavras, ou $66,7 \%$ do total. Já os alunos do grupo C2 forneceram pautas acentuais esperadas para 16 palavras, ou $48,5 \%$ do total.

Por fim, cabe acrescentar que não houve uma palavra que tenha oferecido maior dificuldade a todos os três grupos. As palavras que tiveram menos acertos variaram de grupo para grupo, fato que sugere não haver um padrão acentual mais complexo para os aprendizes. Mesmo algumas oxítonas, como "computador" ou "construção", por exemplo, ofereceram dificuldades. Aliás, a palavra "construção" merece uma nota especial: os percentuais de adequação das pautas correspondem a 46,67\%; 58,33\%; $22,22 \%$ do total, e respectivamente para os grupos B1, C1 e C2. Esta é uma palavra familiar para a maioria dos haitianos, que trabalham na construção civil. Estes índices sugerem que é necessário mais do que a exposição constante a um item, para que os nativos de kreyòl aprendam a localização do acento primário.

15 Por "acerto" entende-se, aqui, a pauta acentual esperada, tal como a elaboraria um falante nativo de $\mathrm{PB}$.

16 Não é possível rodar testes estatísticos para verificar se a diferença de desempenho dos dois grupos é ou não significativa em razão do tamanho reduzido das amostras.

17 Dois alunos dessa turma estavam no Brasil há 15 e 16 meses na época da aplicação do teste. Todos os demais estavam no Brasil há menos de um ano nessa mesma época. 


\section{Considerações finais}

Embora o método para o ensino de alocação do acento primário das palavras em PB tenha começado a ser desenvolvido muito recentemente, os resultados do teste realizado para verificar sua eficácia se mostram muito positivos. Certamente, há pontos a aprimorar, como a questão do shift de acento em casos de derivações, por exemplo. Por outro lado, há pontos que devem ser mantidos: a) a explicitação do funcionamento do acento primário aos alunos; b) a inserção dos exercícios para percepção e produção do acento primário no tema da aula, de modo que sejam usadas palavras que surgem durante as atividades propostas.

Estes aspectos todos sugerem que o método seja útil para a elaboração de um material didático voltado ao ensino de PB para falantes nativos de kreyòl, como deverá ser feito a partir do próximo ano.

\section{BIBLIOGRAFIA}

BAUER, Daniela de Almeida; ALVES, Ubiratã Kickhöfel. O ensino comunicativo de pronúncia nas aulas de inglês (L2) para aprendizes brasileiros: análise de um livro didático. Linguagem e ensino, v. 14, n.2, p. 287-314, jul./dez. 2011.

BISOL, Leda. O acento e o pé métrico binário. Cadernos de Estudos Linguísticos, n.22, p.69-80, jan/jun.1992.

CADELY, Jean-Robert. Les sons du Creòle haitien. The Journal of Haitian Studies, vol. 9, n.2, p. 4-41, 2004.

.Haiti: the politics of language. Journal of Teaching and Education, vol.1, n.3, p. 389-394, 2012.

CANTONI, Maria Mendes. O acento no português brasileiro segundo uma abordagem baseada no uso. Estudos linguísticos, vol.38, n.1, p. 93102, 2009.

FINNEY, Malcolm Awadajin. Tone assignment on lexical items of English and African origin in Krio. In: ESCURE, Geneviève; SCHWEGLER, Armin (eds.) Creoles, contact and language change: linguistics and social implication. Amsterdam: John Benjamins, 2004. p. 220-236.

GROSSO, Maria José dos Reis. Língua de acolhimento, língua de integração. Horizontes de Linguística Aplicada, v. 9, n. 2, p. 61-77, 2010.

MASSINI-CAGLIARI, Gladis. Acento e ritmo. São Paulo: Contexto, 1992. MORAES, João Antonio. Intonation in Brazilian Portuguese. In: HIRST, 
Daniel; Di CRISTO, Albert (eds.). Intonation Systems a survey of twenty languages. Cambridge: The Cambridge University Press, 1998.p. 179-194. SEARA, I.; NUNES, V. G.; LAZAROTTO-VOLCÃO, C. Para conhecer fonética e fonologia do português brasileiro. São Paulo: Editora Contexto, 2015.

SILVA, Adelaide Hercília Pescatori. Melodia da língua portuguesa. PBMIH/UFPR. Manuscrito. 2014.

TARDIEU, Gérard-Marie. Gramè kreyòl. Pòtoprens: Kopivit-Laksyon Sosyal, 2013.

ZIMMER, Márcia; SILVEIRA, Rosane; ALVES, Ubiratã Kickhöfel. Pronnunciation instruction for Brazilians: bringing theory and practice together. Newcastle upon Tyne:Cambridge Scholars Publising, 2009.

Recebido em: 30/12/2014. Aceito em: 04/03/2014. 